Supporting Information for

\title{
C-C Bond Cleavage of Acetonitrile by a Dinuclear Copper(II) Cryptate
}

\author{
Tongbu Lu, * Xiaomei Zhuang, Yanwu Li, and Shi Chen \\ Instrumentation Analysis \& Research Center, and School of Chemistry and Chemical Engineer, \\ Sun Yat-Sen University, Guangzhou 510275 (P. R. China)
}

Materials. All the solvents and chemicals were of A. R. grade and used without further purification. Elemental analyses were determined using a Elementar Vario EL elemental analyser. The IR spectra were recorded in the $4000-400 \mathrm{~cm}^{-1}$ region using $\mathrm{KBr}$ pellets and a Bruker EQUINOX 55 spectrometer. The electronic spectra were recorded with a Shimadzu UV-31010 PC spectrometer.

Experimental Section. The ligand $\mathbf{L}$ was synthesized by a modified literature method: ${ }^{1}$ A solution of 0.009 mol of terephthaldicarboxaldehyde in $150 \mathrm{~mL}$ of $\mathrm{CH}_{3} \mathrm{CN}$ was added dropwise to $0.006 \mathrm{~mol}$ tris(2-aminoethyl)amine in $280 \mathrm{~mL}$ of $\mathrm{CH}_{3} \mathrm{CN}$ over $1.5 \mathrm{hr}$ at room temperature with stirring. After the mixture was stirred for $24 \mathrm{hr}$ the yellow precipitate which formed was filtered out and washed with ether. The yellow solid was then dissolved in $300 \mathrm{~mL} \mathrm{MeOH}$. The solution was heated to $45^{\circ} \mathrm{C}$, and 2.5 $\mathrm{g}$ of $\mathrm{NaBH}_{4}$ was added to the solution with stirring. After the addition of the $\mathrm{NaBH}_{4}$ was complete, the reaction solution was stirred an additional hour, and then cooled. The reaction mixture was evaporated to dryness; $10 \mathrm{~mL} \mathrm{H} \mathrm{H}_{2} \mathrm{O}$ and $100 \mathrm{~mL}$ of $\mathrm{CH}_{2} \mathrm{Cl}_{2}$ were added to the mixture to extract the product. The organic phase was dried over $\mathrm{MgSO}_{4}$ and filtered. The filtrate was evaporated to dryness. The solid was dissolved in $\mathrm{CH}_{2} \mathrm{Cl}_{2}$ again and diffused with ether to get white powder. Yield: $10 \%$. Anal. Calcd for $\mathrm{C}_{36} \mathrm{H}_{54} \mathrm{~N}_{8} \cdot \mathrm{CH}_{2} \mathrm{Cl}_{2} \cdot 5.5 \mathrm{H}_{2} \mathrm{O}: \mathrm{C}, 56.76 ; \mathrm{H}, 8.62 ; \mathrm{N}, 14.31$. Found: C, 56.48, H 8.63, N 14.74;

Caution! Perchlorate salts of metal complexes with organic ligands are potentially 
explosive and should be handled in small quantities with care.

$\left[\mathrm{Cu}_{2} \mathrm{~L}\right]\left(\mathrm{ClO}_{4}\right)_{4}, \mathbf{1}$. To a solution of $\mathrm{L}(0.12 \mathrm{~g}, 0.15 \mathrm{mmol})$ in methanol $(4 \mathrm{~mL})$ was added dropwise a solution of $\mathrm{Cu}\left(\mathrm{ClO}_{4}\right)_{2} \cdot 6 \mathrm{H}_{2} \mathrm{O}(0.167 \mathrm{~g}, 0.45 \mathrm{mmol})$ in methanol (5 $\mathrm{mL}$ ). The mixture was stirred at room temperature for $2 \mathrm{~h}$. The blue precipitate obtained was filtered off, washed with small amount of methanol and dried in a vacuum. Yield: $96 \%$. Anal. Calcd for $\mathrm{C}_{36} \mathrm{H}_{62} \mathrm{~N}_{8} \mathrm{Cu}_{2} \mathrm{Cl}_{4} \mathrm{O}_{20}\left(\left[\mathrm{Cu}_{2} \mathrm{~L}\right]\left(\mathrm{ClO}_{4}\right)_{4} \cdot 4 \mathrm{H}_{2} \mathrm{O}\right)$ : $\mathrm{C}$, 36.16; H, 5.23; N, 9.37. Found: C, 36.38, H 5.44, N 9.26; IR $\left(\mathrm{KBr}, \mathrm{cm}^{-1}\right): 3433$ (s), 3177 (m), 2922 (m), 2877 (m), 1627 (w), 1447 (m), 1101 (s), 1015 (m), 808 (m), 627 $(\mathrm{m})$.

$\left[\mathrm{Cu}_{2} \mathrm{~L}(\mathrm{CN})\right]\left(\mathrm{ClO}_{4}\right)_{3} \cdot \mathbf{2} \mathrm{CH}_{3} \mathbf{C N} \cdot \mathbf{4} \mathrm{H}_{2} \mathrm{O}, 2$. The powder of $\left[\mathrm{Cu}_{2} \mathrm{~L}\right]\left(\mathrm{ClO}_{4}\right)_{4}(0.05 \mathrm{~g})$ was dissolved in acetonitrile $(10 \mathrm{~mL})$ and filtered. The resulting solution was evaporated slowly at room temperature to give emerald green crystals. The yield is almost quantitative. Anal. Calcd for $\mathrm{C}_{41} \mathrm{H}_{68} \mathrm{~N}_{11} \mathrm{Cu}_{2} \mathrm{Cl}_{3} \mathrm{O}_{16}$ : C 40.85, H 5.65, N 12.79; found: C 41.12, H 5.37, N 12.96; IR (KBr, cm $\left.{ }^{-1}\right): 3422$ (s), 3295 (s), 2927 (s), 2878 (m), 2249 (w), 2194 (w), 2143 (w), 2024 (w), 1626 (m), 1446 (s) 1388 (m), 1278 (m), 1093 (s), 1009 (s), 924 (s), 897 (m), 814 (s), 625 (s). MS (FAB): $751\left(\left[\mathrm{Cu}_{2} \mathrm{~L}(\mathrm{CN})\right]^{+}\right)$.

X-ray Crystallography. Crystal data. Complex 2: $\mathrm{C}_{41} \mathrm{H}_{68} \mathrm{~N}_{11} \mathrm{Cu}_{2} \mathrm{Cl}_{3} \mathrm{O}_{16}, M=$

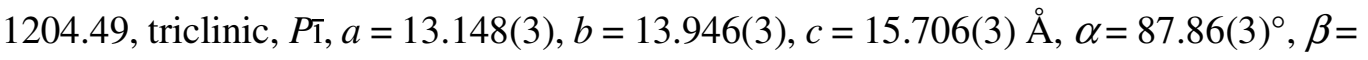
$66.68(3)^{\circ}, \gamma=81.96(3)^{\circ}, V=2618(1) \AA^{3}, Z=2, \rho=1.528 \mathrm{Mg} / \mathrm{m}^{3}, \mu=1.042 \mathrm{~mm}^{-1}$, $F(000)=1256.7502$ independent reflections $\left(\mathrm{R}_{\mathrm{int}}=0.0292\right)$ with $4944[I>2 \sigma(I)]$ observed data, $R_{1}=0.0526, w R_{2}=0.1327[I>2 \sigma(I)]$ and $R_{1}=0.0849, w R_{2}=0.1427$ (all data) with $S=1.081$. Single-crystal data were collected at 296(2) K on a Bruker Smart 1000 CCD diffractometer with Mo-K $\alpha$ radiation $(\lambda=0.71073 \AA)$. The structure was solved using direct method, which yielded the positions of all non-hydrogen atoms. These were refined first with isotropically and then with anisotropically. All the hydrogen atoms bound to carbon were placed in calculated positions with fixed 
isotropic thermal parameters and included in structure factor calculations in the final stage of full-matrix least-squares refinement. All calculations were performed using the SHELXTL system of computer programs. ${ }^{2}$

Selected Bond Lengths $(\AA)$ and Angles (deg) for 2.

\begin{tabular}{llcc}
\hline $\mathrm{Cu}(1)-\mathrm{N}$ & $2.036(6)$ & $\mathrm{Cu}(1)-\mathrm{N}(1)$ & $2.092(4)$ \\
$\mathrm{Cu}(1)-\mathrm{N}(4)$ & $2.144(4)$ & $\mathrm{Cu}(1)-\mathrm{N}(3)$ & $2.148(4)$ \\
$\mathrm{Cu}(1)-\mathrm{N}(2)$ & $2.159(4)$ & $\mathrm{Cu}(2)-\mathrm{C}$ & $1.977(5)$ \\
$\mathrm{Cu}(2)-\mathrm{N}(5)$ & $2.104(4)$ & $\mathrm{Cu}(2)-\mathrm{N}(6)$ & $2.139(4)$ \\
$\mathrm{Cu}(2)-\mathrm{N}(7)$ & $2.159(4)$ & & $2.156(4)$ \\
$\mathrm{C}-\mathrm{N}$ & $1.151(6)$ & & \\
& & & \\
$\mathrm{N}-\mathrm{Cu}(1)-\mathrm{N}(1)$ & $179.2(2)$ & $\mathrm{N}-\mathrm{Cu}(1)-\mathrm{N}(4)$ & $97.3(2)$ \\
$\mathrm{N}(1)-\mathrm{Cu}(1)-\mathrm{N}(4)$ & $83.4(2)$ & $\mathrm{N}(4)-\mathrm{Cu}(1)-\mathrm{N}(3)$ & $96.2(2)$ \\
$\mathrm{N}(1)-\mathrm{Cu}(1)-\mathrm{N}(3)$ & $83.3(2)$ & $\mathrm{N}(1)-\mathrm{Cu}(1)-\mathrm{N}(2)$ & $83.0(2)$ \\
$\mathrm{N}-\mathrm{Cu}(1)-\mathrm{N}(2)$ & $96.7(2)$ & $\mathrm{N}(3)-\mathrm{Cu}(1)-\mathrm{N}(2)$ & $118.2(2)$ \\
$\mathrm{N}(4)-\mathrm{Cu}(1)-\mathrm{N}(2)$ & $119.1(2)$ & $\mathrm{C}-\mathrm{Cu}(2)-\mathrm{N}(6)$ & $97.3(2)$ \\
$\mathrm{C}-\mathrm{Cu}(2)-\mathrm{N}(5)$ & $179.1(2)$ & $\mathrm{C}-\mathrm{Cu}(2)-\mathrm{N}(7)$ & $96.4(2)$ \\
$\mathrm{N}(5)-\mathrm{Cu}(2)-\mathrm{N}(6)$ & $83.5(2)$ & $\mathrm{N}(6)-\mathrm{Cu}(2)-\mathrm{N}(7)$ & $117.5(2)$ \\
$\mathrm{N}(5)-\mathrm{Cu}(2)-\mathrm{N}(7)$ & $83.6(2)$ & $\mathrm{N}(5)-\mathrm{Cu}(2)-\mathrm{N}(8)$ & $82.6(2)$ \\
$\mathrm{C}-\mathrm{Cu}(2)-\mathrm{N}(8)$ & $96.5(2)$ & $\mathrm{N}(7)-\mathrm{Cu}(2)-\mathrm{N}(8)$ & $119.2(2)$ \\
$\mathrm{N}(6)-\mathrm{Cu}(2)-\mathrm{N}(8)$ & $119.3(2)$ & $\mathrm{C}-\mathrm{N}-\mathrm{Cu}(1)$ & $179.7(4)$ \\
$\mathrm{N}-\mathrm{C}-\mathrm{Cu}(2)$ & $179.5(4)$ & $\mathrm{N}(3)-\mathrm{C}(15)-\mathrm{C}(16)$ & $109.1(4)$ \\
$\mathrm{N}(2)-\mathrm{C}(3)-\mathrm{C}(4)$ & $110.2(4)$ & $\mathrm{N}(6)-\mathrm{C}(10)-\mathrm{C}(7)$ & $109.6(4)$ \\
$\mathrm{N}(4)-\mathrm{C}(27)-\mathrm{C}(28)$ & $109.4(4)$ & $\mathrm{N}(8)-\mathrm{C}(34)-\mathrm{C}(31)$ & $109.0(4)$ \\
$\mathrm{N}(7)-\mathrm{C}(22)-\mathrm{C}(19)$ & $108.2(4)$ & & \\
\hline
\end{tabular}



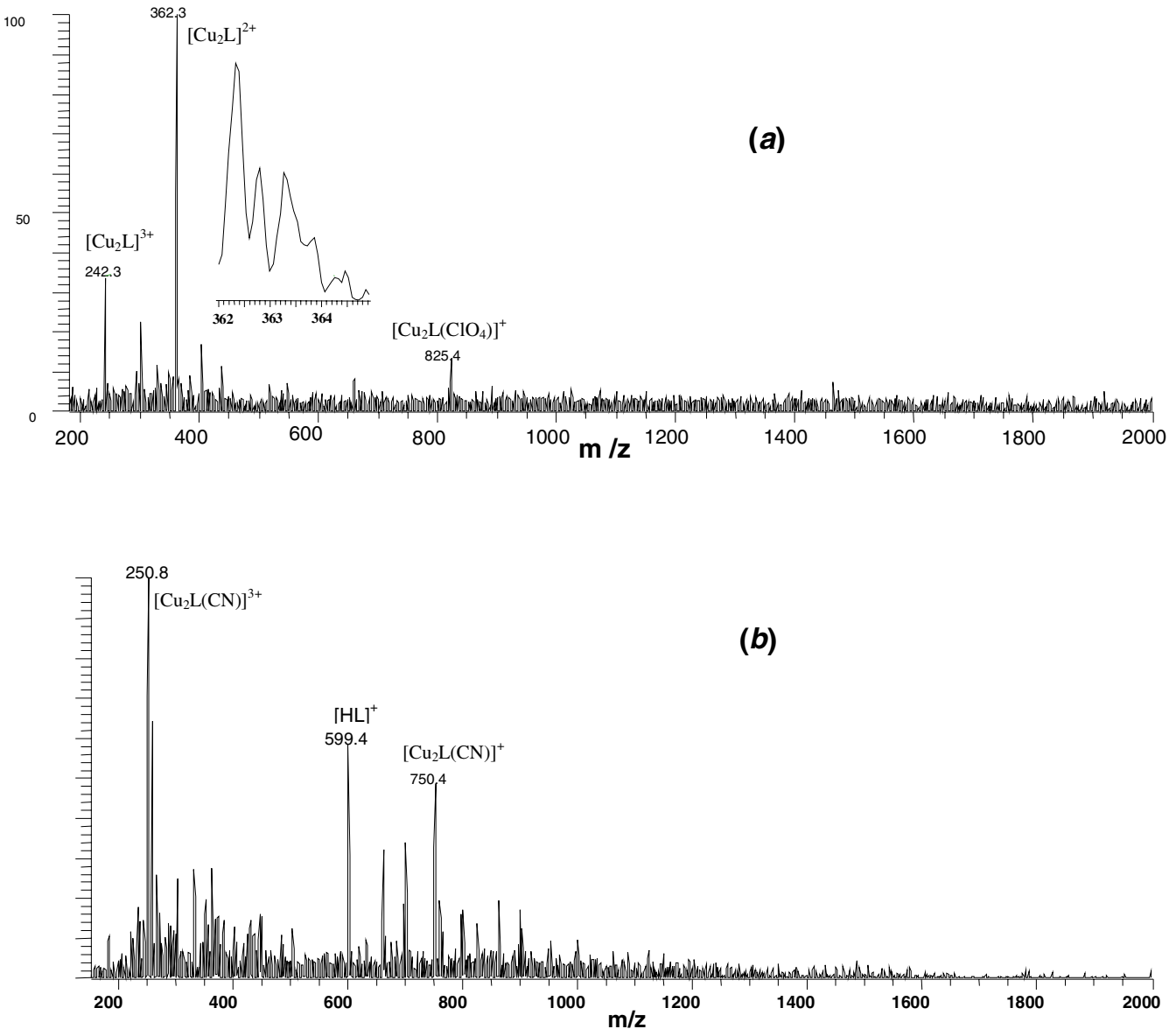

Fig. S1. ESI mass spectra of $\mathbf{1}$ in acetonitrile (a) before, and (b) after heating. 


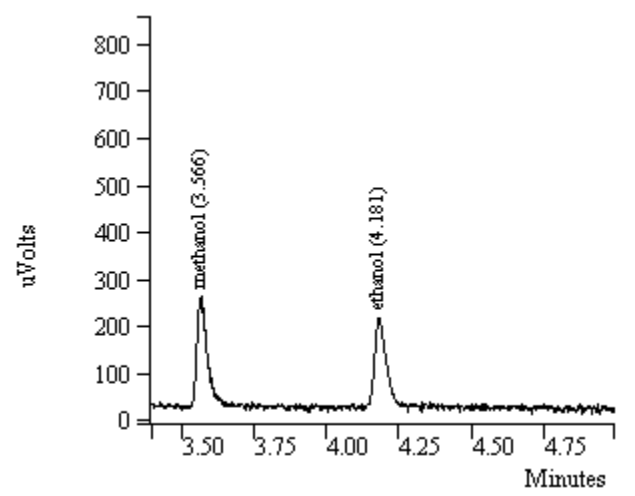

Fig. S2a. The GC spectrum of the solvent (acetonitrile , HPLC Grade, refluxed with $\mathrm{CaH}_{2}$ under Argon atmosphere before using) on HP-INNOWax polar column, showing methanol and ethanol impurities exist in the solvent.

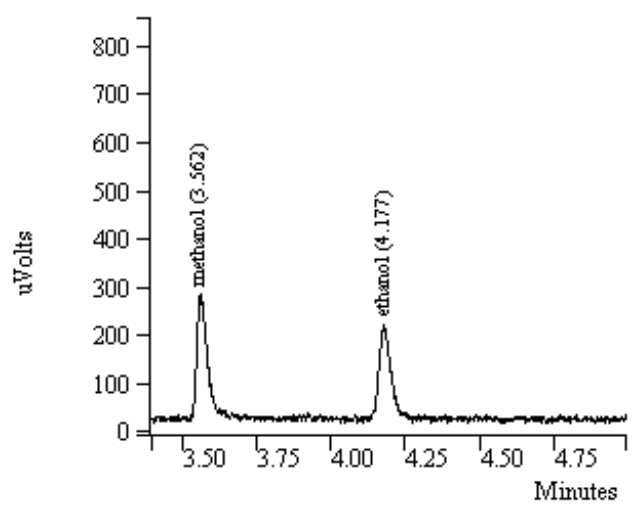

Fig. S2b. The GC spectrum of the solution of $\mathbf{1}$ in acetonitrile (measured immediately after dissolving) on HP-INNOWax polar column, the amount of methanol has increased 10\% compared with that in the solvent. The amount of ethanol keeps constantly. This indicates 1 reacted with acetonitrile quickly once mixing.

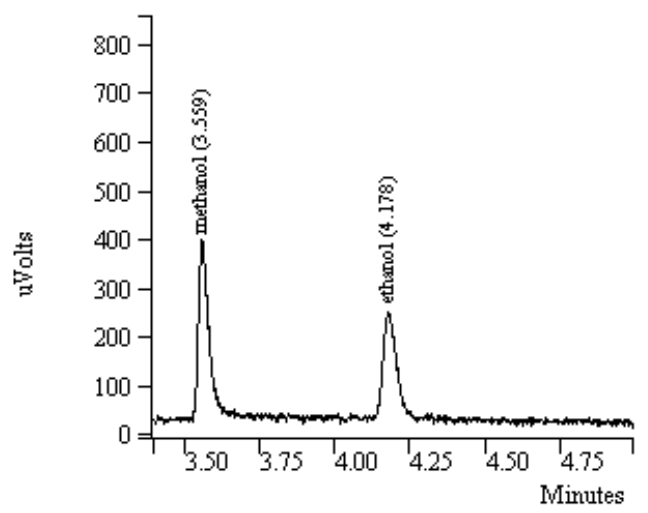

Fig. S2c. The GC spectrum of the solution of $\mathbf{1}$ in acetonitrile (after standing at room temperature for one day) on HP-INNOWax polar column, the amount of methanol has increased $60 \%$ compared with that in the solvent. The amount of ethanol almost keeps constantly. This clear indicates that methanol is produced during the reaction of $\mathbf{1}$ with acetonitrile. 


\section{S3: Determination of cleavage rate constant}

Compound 1 was dissolved in the mixture solution of acetonitrile and water to get

a concentration of $5.08 \times 10^{-4} \mathrm{M}$, the absorbance was recorded every 30 minutes at $\lambda=$ $890 \mathrm{~nm}$ and $20^{\circ} \mathrm{C}$.

In the presence of excess acetonitrile, the rate law can be described as:

$$
\mathrm{d} C_{\mathrm{A}} / \mathrm{d} t=-k C_{\mathrm{A}}
$$

where $C_{\mathrm{A}}$ is the concentration of $\mathbf{1}$ at time $t$.

$$
A_{\infty}-A_{t}=\varepsilon b\left(C_{2(0)}-C_{2 t}\right)=\varepsilon b C_{\mathrm{A}},
$$

where $A_{t}$ is the absorbance of the resultant (2) at time $t, A_{\infty}$ is the absorbance of the resultant (2) when the reaction completes (the absorbance shows no obvious change within one hour).

$$
-\ln C_{\mathrm{A}}=-\ln \left(A_{\infty}-A_{t}\right)=k t+B
$$

The plots of $-\ln \left(A_{\infty}-A_{t}\right)$ versus time at different concentrations of water are shown as following:

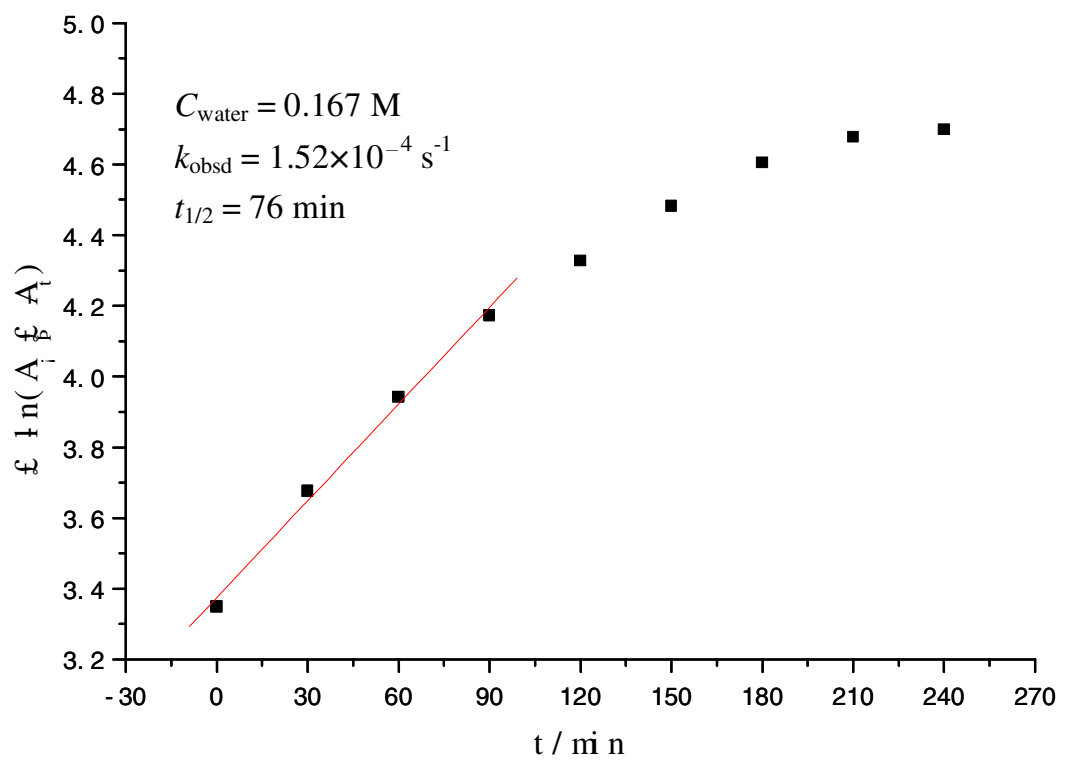



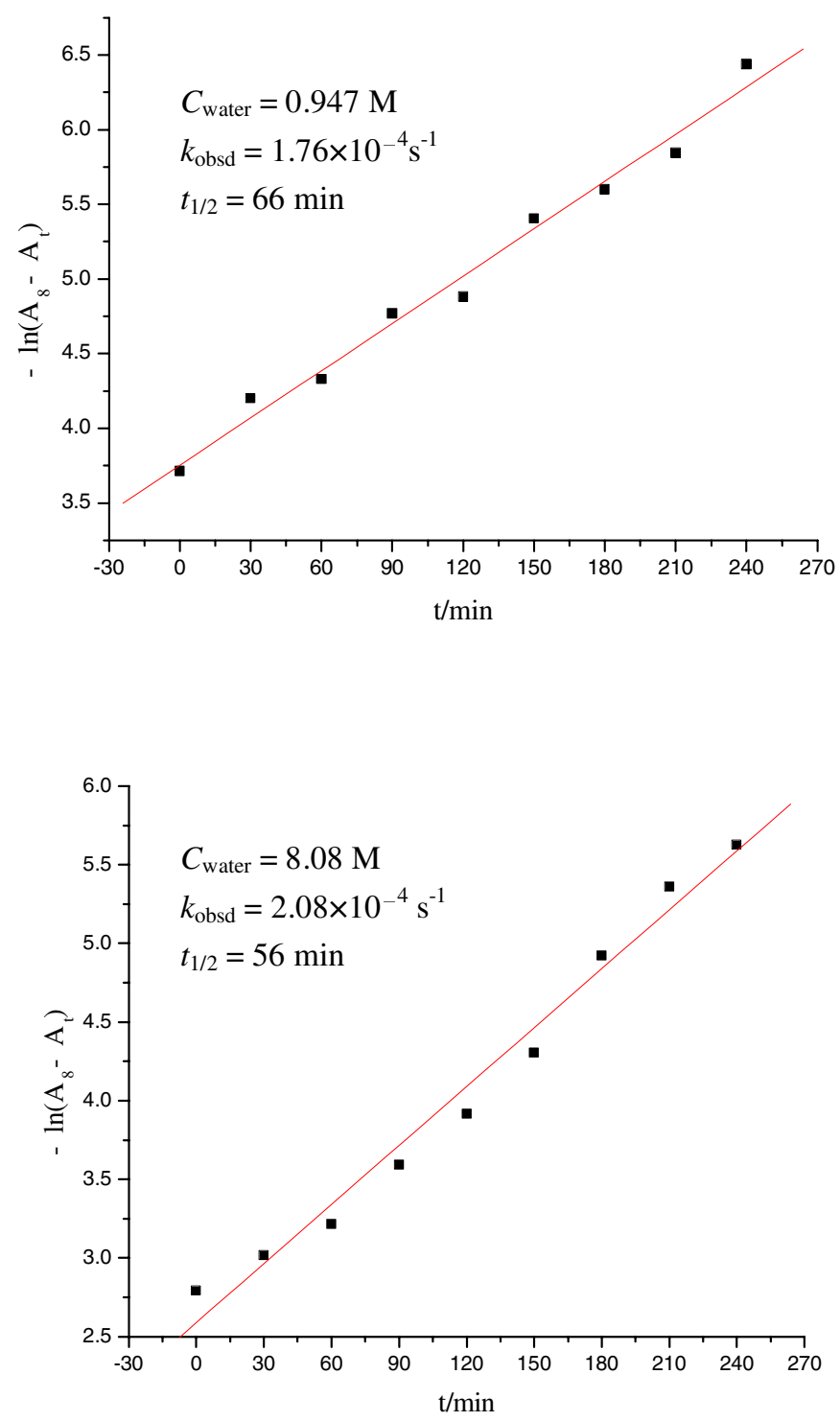

The calculated second order rate constant $\left(k_{2}\right)$ and $\alpha$ value are $1.76(1) \times 10^{-4} \mathrm{M}^{-1} \mathrm{~s}^{-1}$ and $0.084(2)$, respectively according to the followung equation: $k_{\mathrm{obsd}}=k_{2}\left[\mathrm{H}_{2} \mathrm{O}\right]^{\alpha}$ 


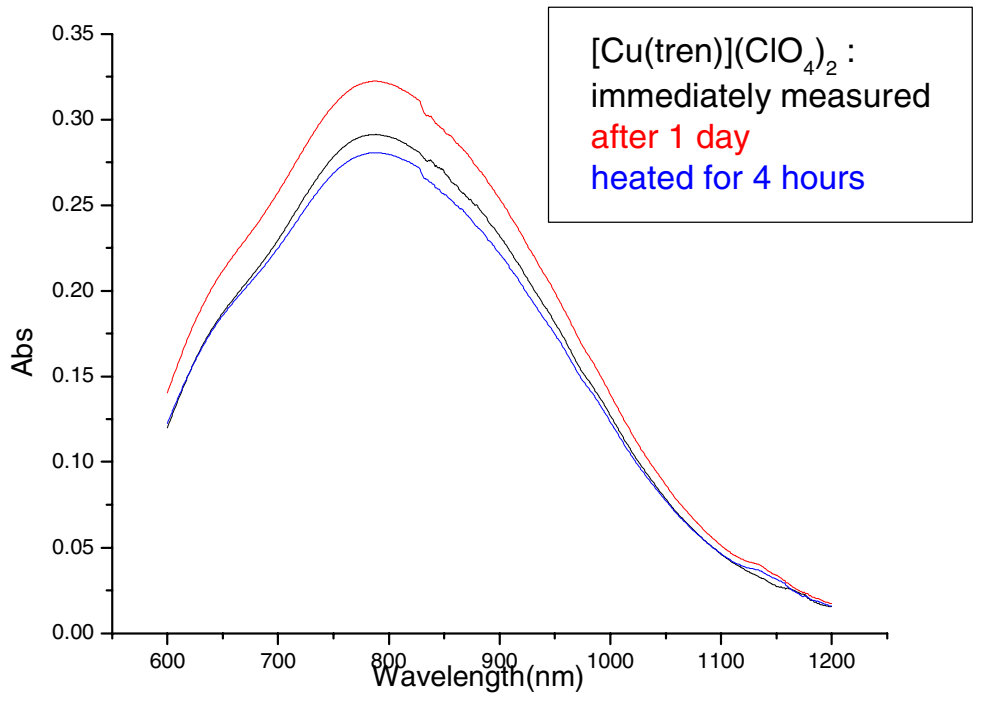

Fig. S4. The electronic spectra of $[\mathrm{Cu}($ tren $)]\left(\mathrm{ClO}_{4}\right)_{2}$ in acetonitrile as a function of time, showing the absorption bands did not change after standing and heating, indicating there is no reaction between $[\mathrm{Cu}($ tren $)]\left(\mathrm{ClO}_{4}\right)_{2}$ and acetonitrile.

\section{References}

1. Chen, D.; Martell, A. E. Tetrahedron, 1991, 47, 6895.

2. Sheldrick, G. M. SHELXL 97, Program for Crystal Structure Refinement, University of Göttingen, Germany, 1997. 